\title{
Horváth \& Kiss v. Hungary: How Romani children became mentally retarded
}

\begin{abstract}
In 2013, the European Court of Human Rights decided the case of Horvath and Kiss v. Hungary in favor of the two Romani boys who alleged that they had been misdiagnosed as 'mildly mentally retarded' and consequently placed and retained in a special school for their whole primary education. This, they claimed, deprived them of the educational opportunity to pursue their chosen vocational interests. In this research note, I will provide a brief view of the history of special education in Hungary, and the history of mental retardation in its medi$\mathrm{cal} /$ pedagogic connections. I will suggest that the Court's decision, while a positive development, fails to address the fundamental systemic racism of the entire medico/educational system in Hungary, and that until that more radical change is undertaken, a disproportionate number of Romani children will continue to be officially and unofficially treated as mentally deficient.
\end{abstract}

Keyword: children, Hungary, mentally retarded, Romani

$$
* * *
$$

That Romani students continue to be systematically devalued and underserved by public schools across Europe is not in question. This fact has become for Europe and the EU, as civilized and civilizing entities, the latest historical manifestation of the perennial 'Gypsy problem.' In communist Europe of the 1960s, the problem - from the point of view of the powers that be - was not so different. Here was an unassimilated minority not enjoying the kind of socially equality and prosperity on which the socialist State had waged its fortunes. In neoliberal Europe of the 2020s, the very same systemic racism pervades public institutions, and some kind of positive response is called for. The educational problems of Romani students has been addressed, among other ways, through a legal campaign - aimed at the European Court of Human Rights (ECtHR) in Strasbourg - that seeks to persuade mostly post-communist nations to desegregate their schools, to make space for Romani students in the mainstream. The current segregation problem was pro- 
duced in large part through the failed attempt to solve the 'Gypsy problem' of the early 1960s, when the twinned goals of industrial growth expansion of compulsory schooling encountered a large Romani population that didn't take up, and was not permitted to take up, the offer of total assimilation. The result was that Romani children were put in schools, but not into normal mainstream schools, but into either segregated 'ghetto' schools or segregated special schools for the mentally defective (McCagg, 1991; Majtényi and Majtényi, 2016; Eliason, 2016).

In this note, we will look at the most recent major ECtHR Romani education case - Horváth E Kiss v. Hungary (2013) - decided in appearance in favor of the two plaintiffs, Romani boys who were diagnosed as mentally retarded and placed and retained in a special school until their teen years, after which their life chances were severely limited. These two young men are representative of a large, international class of Romani children who have been placed on dubious grounds in special schools for the mentally handicapped over the past fifty years. Our limited purpose here will be to detail the grounds of the complaint, and the response of the Hungarian state to this complaint, focusing on the medico-pedagogic classification of 'mental retardation' (intellectual or cognitive disability, oligophrenia, backwardness, feeblemindedness, idiocy, subnormality, et al.). To better understand what it means to have been classified as mentally retarded in Nyergihyáza, in eastern Hungary, in 2000 we need to learn something about the historical development of Hungarian special education, working backward from the articulation of the current framework in the 1970s.

One purpose of this historical expedition will be to suggest that the remedies proposed by the Court, or by other European entities with like missions, are not sufficient to address the deep institutionalization of racial animus against Roma in schools. My contention is that nothing the Court has decided fundamentally changes the underlying logic of the system by which Romani children are presumed inferior, of diminished value, and treated as such. It is important to keep in mind that this conclusion does not mean to pick out countries like Hungary - as easy target with its current antidemocratic leadership - as exceptional, that is, as somehow less civilized than European nations with longer traditions of at least pretending to be democratic. Rather, it is the clear example of permanent systemic racism in education (and elsewhere) provided by leaders of the EU, and the United States, that make it easier to see what's going on in places like Hungary. 


\section{The background of the case}

In Horváth and Kiss v. Hungary (2013), The ECtHR upheld the boys' complaint, ruling that schools and school officials has discriminated against them on the basis of their Roma ethnicity, violating Article 14 (which prohibits discrimination generally), and Protocol 1, Article 2 (which specify the right to education) of the European Convention on Human Rights (Barnes, 2017). This case focuses on the detail of the diagnostic processes by which these two boys - both seven years old at the time of their first examinations in 2001 and 2000 respectively - were determined by school authorities to be mentally retarded and in need of placement in remedial (special) school settings. They were tested on numerous measures over the course of the next five years, and a complaint against the Expert Panel responsible for the diagnosis, alleging unequal treatment, was filed on their behalf in the county court in 2006. It was another seven years before the case was decided, by which time both boys had left school.

András Horváth and István Kiss do not exactly appear 'in person' in this text, but rather they alternate between being represented as artifacts of their official records and as holders of rights to education. Their first names are never mentioned and they are always referred to as 'young men,' when in fact they were at the time this case was originally filed 11 and 13 respectively, and the violation of their right to education that this judgment acknowledges occurred first when they were each seven years old. That is, when they were officially deemed 'mentally disabled' and placed in a special school for the handicapped. The only personal information shared in the report is that András wanted to be a dance teacher, like his father, and that István wanted to be an auto mechanic. Neither was able to pursue those vocations because they were not permitted to attend the secondary school where the requisite skills might have been learned. This deprivation - which did not enter into the actual legal arguments - was offered rhetorically at the outset to illustrate the damage done by their placement in the special school. The document omits mention of the fact that only a small minority of Romani students generally, including who are not placed in special classes, manage to complete a secondary program leading to skilled employment.

In 2001, when he was six or seven, Mr. Horváth was referred by his preschool teachers and administration to an 'Expert Panel' on the observation that 'his mental and social abilities were lower than normal for his age,' and 
reasonable suspicion that he was mentally disabled. The 'Expert Panel' - on the bases of three 'intelligence' tests that delivered disparate results - determined that he was more than two years behind his normal peers academically, and classified him as having 'mild mental disability', They suggested that his central nervous system was immature, but offered no further organic basis for his disability. This diagnosis triggered placement in the Göllesz Viktor Remedial Primary and Vocational School, where he remained until at least 2008. Over that period, he was tested several times, and although his school performance and attendance were good, and teachers said that his borderline IQ score (of 71) underestimated his abilities, the Expert Panel chose not to alter either his diagnosis of 'mild mental disability' or his placement in the remedial school.

In 1999, during his first year in the regular primary school located in the Romani settlement in Nyíregyháza, Mr. Kiss (age seven) was placed in a special program within the school, due to 'learning difficulties deriving from his disadvantaged social and cultural background.' The following winter he appeared before the Expert Panel, who diagnosed him also with 'mild mental disability' on the basis of two IQ tests - the Budapest Binet Test, a mostly verbal measure, and Raven's Progressive Matrices, a visual measure: there was considerable discrepancy between his scores on these two measures, yielding an average of 73. His parents objected to his removal from the regular primary school and his placement in the Göllesz Viktor Remedial Primary and Vocational School, to no avail, and were not afforded their legal option to appeal the decision. István was a model student at the special school, won several awards, and subsequent IQ tests conducted by independent experts found his abilities to be in the normal range. The official school authorities disagreed and he remained in the special school and then was referred to the special track in the secondary school, where he was not able to pursue study of auto mechanics. The Court's narrative of the boys' school histories ended in 2008, after charges of discrimination were filed on their behalf in 2006 by Lilla Farkas, in conjunction with the Chance for Children Foundation and the European Roma Rights Center.

The case began at the local level, and proceeded on appeal up to Hungarian Supreme Court, who referred it to the European Court of Human Rights. As Farkas notes, it was the express purpose of bringing this case to extend the ruling in $\mathrm{DH}$ and others $v$. $\mathrm{CZ}$ to address issues of discrimination left unresolved in that case, particularly questions related to intelligence testing itself, and its use in the disproportionate diagnosis of Romani children as mentally disabled, leading to placement in special schools. 


\section{Diagnosing mental retardation/ deficiency}

The goal of the boys' lawyers was to prove discrimination by showing that they were treated 'differently, without an objective and reasonable justification, [than other] persons in relevantly similar situations.' The other persons would be young Roma and non-Roma children who might have been referred by their teachers and other professionals for evaluation, because they were not making adequate progress in school, or in pre-school. The Roma boys, and comparable non-Roma children for that matter, were already in segregated environments in their own neighborhood schools before they were transferred to special schools. The lawyers asserted (p. 23) that the special education system in place did in fact 'uniquely burden' their clients, in at least three ways. First, they claimed (p. 32) that the Expert Panel - an interdisciplinary medical/pedagogical team under the supervision of the County council who administered the prescribed tests - did not properly inform the parents of the process, or obtain their consent for the eventual diagnoses and placements. Second, they notes that the Public Education Law (PEA) continued to permit the Expert Panel to use the concept of 'familial disability', which in effect rendered being poor and being Roma a de facto disability, and was therefore discriminatory. Finally, the attorneys for Horváth and Kiss referenced a revision to the PEA that disallowed placing children with learning or other psychological difficulties, but without evidence of mental deficiency from 'organic' causes, in special schools, and claimed that the test results did not provide that evidence, and in any case barely met, or did not meet, minimal criteria for mental retardation. While there was a great deal of discussion of the validity and bias of the testing materials themselves, counsel did not formally make any formal claim that they were in themselves discriminatory.

Lawyers for the Hungarian government denied that these Roma children had been treated less favorably that non-Roma children in the same situation, and that while their educational treatment had turned out to be different than some non-Roma and some Roma children, there was good justification for this difference. The boys were shown to be mentally deficient, with special needs that could not be met in the regular school. By way of answering both the claims that the family disability concept was useful and valid, and that there was nothing objectionable about the testing, the Government asserted (p. 25): 
that tests and standards tailored to the Roma population would have no sensible meaning from the point of view of assessing a child's ability to cope with the mainstream education system - which was the purpose of the assessment of learning abilities of children and of the psychometric tests applied in the process ... The Government claimed that socio-cultural background had been decisive for the mental development of the child, and when the actual level of a child's mental development (IQ) had been measured, the result had necessarily been influenced by the same socio-cultural effects that had shaped the child's mental development.

With respect to the argument that this placement was inappropriate because the Expert Panel had not found any evidence of the organic basis of mental deficiency that was supposed to be a condition of placement into this school, the government pointed to a new provision to the PEA allowing the placement of learning disabled children in the special school if they were provided with an appropriate developmental plan, which they said that the Expert Panel had provided. They denied that the Expert Panel had even diagnosed Horváth and Kiss as 'mentally retarded', the question of misdiagnosis was moot.

The Court ruled in the boys' favor only in regard to the failure of the Expert Panel to provide due process to the parents of the children, which resulted in a placement that deprived the boys of their educational rights, that is, prevented them from pursuing the kinds of vocations they wished to pursue. They added that the government was responsible for taking special care in decisions about Roma education because of their historical record of vulnerability to unequal treatment. The government failed in this regard also. While the Court raised questions about the fairness of the testing, and about the discrepancies between the criteria used by the Expert Panel in determining mental retardation and the criteria recommended by the World Health Organization, it declined to rule on whether these arrangements violated the Convention on Human Rights. As is typical in such cases, the Court gives wide deference to States to determine how to educate and medically treat their students, leaving it to the schools to decide - in almost every case which differences in treatment are justified and which are not. 


\section{Institutional foundations of segregation on the basis of mental deficiency}

It might seem that the circular argument employed by the State to justify their policies could never be refuted, without fundamentally uprooting some its major premises, which are grounded in the institutional practices and logics that the Court is reluctant to address. I would contend that this is the main source of the weakness of a strategy for improving the lives of Romani children and families primarily through legal challenges. The law, particularly the European law as it is currently constituted, lacks the power the challenge the social and political practices underlying schooling (and the associated medical, 'scientific' institutions) at the level at which they would need to be challenged, if an equal education for Roma children was an issue really on the table. The Court can't change what many/most Hungarian authorities think about Roma, it can't change how mental retardation has been 'weaponized' (to use the current jargon) in the service of eugenic (racial) reasoning, and it can't change the deeply-held convictions about homogeneous grouping (nonintegration) on which almost all European school systems are constructed.

There is nothing unique about Hungary in this regard: it has its unique history and socio-political formation, but the general outlook on full-throated cultural integration there is not significantly different that what one finds in Paris, London, Berlin, or Chicago. In the remainder of this note, I would like to sketch some of the particularities of the official Hungarian perspective, with respect to the two main issues raised (but not actually ruled upon) in this case: the concept of family disability, and the meaning of mental retardation (and its many discredited synonyms). To this end, I will review a series of reports published in 1982-83 by a group of physicians, scientific researchers, and experts in education under the aegis of the National Institute of Hygiene in Budapest [citation]. These reports summarize the concept of family disability, in the context of the history of special education as it has applied to the Roma in the communist period. The results of their study are cited in the Court papers, but not described in detail. Much more could be said about the history of this perspective and related policies and practices - looking back to the continuing influence of Heilpädagogik in Hungary, first felt at the turn of the $20^{\text {th }}$ century; the uncomfortable history of eugenics in Hungary, culminating in the mimicking, and cooperation with, the Nazi genocide; and 
the domination of the Russian science of abnormality, termed defektology, starting in the 1950s. But that will need to wait for another occasion.

\section{Family disability and criteria for mental retardation (1970s)}

In the early 1980s, an interdisciplinary group of scientists, doctors, and educators from Budapest published three papers delineating the situation with regard to mental retardation in Hungary (Cziezel, 1980; Szondi and Sentágothai, 1981; Lanyi-Engelmayer, Katona and Cziezel, 1983). These publications also detailed a large-scale study of diagnoses of mental retardation from 1971, which gives a dramatic sense of the role of 'family disability' in the diagnosis of mental retardation in children, and in their placement in special schools. This was a period in which the education and literacy of Roma children was perceived, as it was forty years later, to be a social and political problem of some urgency: while many more Roma children were in school in the 1970s than had ever been the case, most did not progress beyond elementary school, and upwards of $30 \%$ of Roma children were classified as mentally deficient. Most of these children were placed in some kind of special school or special 'Gypsy' class (Crow, 1991). Much of this 'mental deficiency' seemed to derive from a lack of knowledge of the Hungarian language, and from poor school attendance.

'Mental retardation' was used at the time interchangeably with mental deficiency, oligophrenia, mental insufficiency, mental subnormality to refer to this class of children who were eventually referred for some kind of care or treatment. There were four categories of mental deficiency - mild, moderate, severe, and profound - with the only a small percentage of cases assigned to the first three categories: perhaps . $3 \%$ of the total $3.3 \%$ of the total population designated as mentally deficient as this time. The mild mental retardation - the category into which Horváth and Kiss were placed - corresponds to IQ scores between 50 and 70, though policies in the late 1990s when they appeared before the Expert Panel permitted a diagnosis when IQ scores were somewhat above the threshold of 70, as was the case for both boys on several measures of intelligence.

There are three main criteria for mental retardation: (1) social incompetency, (2) significantly low IQ, (3) and disturbance in mental development. The social criterion is determined (diagnosed) by parents and teachers, however, sometimes it is confirmed with the help of special 
tests (e.g., Vineland). At school-age the social incompetency is manifested as educational retardation or incompatibility. Later, lack of social competence and/or lack of self-sufficiency are the most important (Lanyi-Engelmayer, Katona and Cziezel, 1983, p. 125).

The authors go on to define the two etiologies from which mental deficiency develops: a pathological, anomalous category characterized by presence of genetic, physiologic, of somatic abnormalities, and a familial-cultural source which is not based on either evidence of organic abnormalities or family histories of genetic or other organic disorders.

The latter variety of mental deficiency - corresponding to the diagnostic criteria of 'social incompetency' - is 'determined (diagnosed) by parents and teachers, however, sometimes it is confirmed with the help of special tests ... At school-age the social incompetency is manifested as educational retardation or incompatibility. Later, lack of social competence and/or lack of self-sufficiency are the most important' (p. 126).Traditionally, and in the case of these professionals in the 1980s, it was the understanding and treatment of those children in the first category - usually with the more severe problems - that was of primary interests to the medical/psychiatric field, and this class of mentally retarded individuals was at the time shrinking, due to medical advances and public health measures (Tusnadys, 1980; Szondi and Sentágothai, 1981).

Important to note here - and this practice has not changed in the succeeding four decades - is the fact that mental retardation as social incompetency, not fitting in, is defined almost exclusively as behavior within the school setting, where teachers (and in practice, somewhat less frequently) parents are responsible for the first referral. The medical (psychiatric) and psychological (psychometric) participants in the process of diagnosis join with the purpose of confirmation, or disconfirmation, of this initial diagnosis. While some of the tests employed in making their determination tap 'daily living skills', most of the tests (like the Binet and Wechsler tests) are highly correlated with school performance, and with the schooling histories of parents. This produces, of course, a situation of self-fulfilling prophecy. Children are selected out by teachers and counselors for not exhibiting conventional, age-appropriate (indexed to 'normal' non-Roma children) behaviors and academic performance, and the tests confirm the teacher's observations, but add the psychiatric designation of mental retardation, which enables removal from integrated regular classroom setting to a segregated remedial setting. 
Lanyi-Engelmayer, Katona and Cziezel (1983) note special schools in the Hungarian tradition are not typically inclined toward the goals of integration. Rather, special education in Hungary 'regards optimal developmental programs for disabled persons as those most greatly stressing orthopedagogical goals.' The practice and theory of orthopedagogics emphasized the problems of particular children in achieving adulthood, and in cooperating with adults. While often dressed up in the language of phenomenology (as in the example quoted below, from the same time period), this was basically a behavioral, correctional - as opposed to curricular - approach to (remedial) education, where adults seek to recognize 'his problem' and to correct it.

In a problematic educative situation there are noticeable moments of aggravation in the relationship between child and adult that have to be dealt with adequately. ... That a particular child's becoming adult does not occur as it should usually is noticeable because on the basis of particular behaviors he becomes conspicuous, especially in the sense that they are not in accord with what can be expected of him in everyday interactions. Being rebellious, telling falsehoods, neglecting obligations, manifesting learning and/or behavior problems indeed make a child conspicuous. These symptoms are nothing more than an indication of a gap between his achieved level of becoming adult and his presently achievable level. Also, this is a summons to the adults to now engage in "special" intervention with him and to help him with "his problem"... Thus, for example, Adam did not ask Eve what problematic educating is but what now has to be done with Cain (Niekerk, 1979, p. 23).

Indeed, what now has to be done with Cain! Lanyi-Engelmayer, Katona and Cziezel (1983, p. 125) go on to suggest that the placement of so many children into special schools on the basis of social incompetency - where there is no evidence of organic injury or defect - and the lack of integration between the goals of normal and special education is due 'the achievementoriented, pedagogically intolerant atmosphere of ordinary public schools, crowded classes, and limited possibilities of individual teaching.'

In 1971, Cziezel et al. (1980) carried out the first large-scale etiological study of mental retardation in children in Hungary. The study was comprised of many evaluative components: anthropometric, psychometric, medical, psychiatric, pedagogical, and socio-demographic. This multi-disciplinary approach to mental retardation, where the underlying condition is defined as medical/ psychiatric and the treatment as predominantly educational, bears witness to the heritage of Hungarian special education in Heilpädagogik, which origi- 
nated in Germany in the late $19^{\text {th }}$ century, as well to the influence of Russian Defektology during the communist period. In both cases, the subordination of education to psychiatry should be noted, as well as extent to which psychiatric power is grounded in the law. This, of course, is clear in the case Horváth and Kiss, who are legally 'confined' in the special school, constrained from entering the regular school, on the basis of the legal authority of Expert Panel. The study in 1971 revealed the extent to which the 'social competency' criteria of mental retardation, associated with an etiology of family-cultural disability, had come to dominate the diagnostics of mental deficiency in Hungary.

Only $31 \%$ of the 1364 children examined were diagnosed with 'pathological' mental retardation, while $49 \%$ were diagnosed with 'familial-cultural' causes, and another 19\% with no known cause, or no diagnosis of mental retardation at all. There is no mention of Roma, specifically, in the discussion of familial-cultural disability, but it is certain from the historical context (Matenji \& Matenji, 2016) that Roma children must have constituted a large portion of this category. It's worth going into some detail about the operation logic of the diagnostic category, because it give some sense of how not fitting into school is brought into contact with biopolitical factors like reproductive practices (Pickette, 2015). The authors (p. 124) begin by asserting that 'genetic (polygenic) and environmental influences play interrelated roles in the development of intelligence in general and as causal agents of familialcultural mental retardation.' The children in this category were found to be approximately 12 times as likely to have siblings and parents who were also mentally retarded as in a 'control' population. Again, while there is no specification of anyone's ethnicity in this study, we must assume that Roma children were overrepresented in 'retarded' group and underrepresented in the 'normal' group, an inference also supported by low SES and low vocational levels of the mentally deficient families.

One might have asked whether this is just a function of socio-economic deprivation, that is, whether mental retardation is an environmental rather than some kind of endogenous, familial-as-genetically-related, consanguinity effect. But the authors point to data related to 'fertility' and reproduction. 'The number of children in families with mild familial-cultural retardation was more than twice the average in the general population ... This high fertility rate, probably due to ignorance of birth control methods, may have contributed to the high prevalence of retarded people and the relatively frequent occurrence of retarded parents in this category' (Cziezel, 1980, p. 127). The 'fertility' of Roma women, their reproductive behavior, and the birth-weight 
of their children, had been (and continues to be) a preoccupation of Hungarian public health authorities for many years, and many orthopedagogical interventions were attempted, including various forms of coerced sterilization (See Szénássy, 2017, for example). These speculation with respect to family 'degeneracy' are consistent and continuous with the rationalizations of eugenic science that prevailed in Hungary, and other states under the Nazi sway, during the fascist period (Varsa, 2017). But it's also important to recall that this perspective about mental retardation and the marginalized, racial minority communities who were overrepresented in the pool of those diagnosed as mentally retarded and placed in special schools, was common across Europe and the United States at the time (Sarason and Doris, 1979; Clarke and Clarke, 1974). It was 'normal' science and normal social policy. This research from Hungary was presented in 1973 at the International association for the scientific studies of mental deficiency, then and still, with 'intellectual disability' having replaced 'mental deficiency', the major scientific organization devoted to the subject.

\section{Conclusions}

The inclusion of concept of family disability (with its undisguised relation to the 'Gypsy problem') in the criteria for the psychiatric diagnosis of mental retardation remained part of the Public Education Law in Hungary into the 21st century. The system of special schools was likewise little changed from it's initial expansion and rationalization in the 1960s and 1970s. It's important to note that the population identified in Hungary (and other countries) as Roma is tremendously diverse, and that while for some segments of this population there has been an increase in educational opportunities and integration over the past fifty years, for other segments - those found in the poor rural and urban settlements across the country - things are not much improved. The 'Decade of Roma Inclusion' that concluded in 2015 did not deliver the promised inclusion, and the hard rightward, nativist turn of the government of Hungary has supported overt anti-Roma sentiment, action, and policy. But the more obscure point I would like to emphasize is that it is the official, scientific, legal definition of the category of mental retardation - and the way that this definition determines placement in a particular set of medico-educational institutions - that undermines the possibilities for overcoming the kind of non-inclusion litigated in Horváth E Kiss v. Hungary. Like the other ECtHR cases decided in favor of Roma plaintiffs since 
2007, the achievements related to process, to recognition of rights, and to the public awareness and pressure for reform are significant and very important. But they have so far failed to gain sufficient leverage to change the underlying structures and logics that keep Roma children down, that render them 'mentally deficient' in order to remove them from integrated educational spaces from which high quality secondary, not mention higher, education might be accessible.

I would like to return here at the end to the reasoning of the Hungarian government in favor of placing and retaining Roma children like András Horváth and István Kiss in special schools, under the yoke of diagnoses of educational insufficiency. They claim that tests and standards tailored to the Roma population would have no sensible meaning from the point of view of assessing a child's ability to cope with the mainstream education system which was the purpose of the assessment of learning abilities of children and of the psychometric tests applied in the process ... The Government claimed that socio-cultural background had been decisive for the mental development of the child, and when the actual level of a child's mental development (IQ) had been measured, the result had necessarily been influenced by the same socio-cultural effects that had shaped the child's mental development.

What they are saying here is that it the very notion of unbiased tests or misdiagnosis misunderstands - from their point of view - how public schools actually work, and who they work for. Even the reform of the law to make evidence of some kind of organic involvement pre-requisite for the official diagnosis of mental retardation has not significantly the process or structure of the normal/special school relationship. Placement in special schools has been expanded to include those without obvious organic involvement but who have other learning and psychological problems that disqualify them from inclusion in mainstream schools. The maintenance of strong cultural (and 'scientific') beliefs in the racial reality of 'family and cultural disability', and the institutionalization of these beliefs in the medico-pedagogic structures of special education, serve as a guarantee that inclusion for a large group Roma students will not be realized.

\section{Bibliography}

Barnes Kristen, G. 2017. Adjudicating Equality: Anti-discrimination education jurisprudence in the European Court of Human Rights. Harvard Journal on Racial \& Ethnic Justice. 33, pp. 202-249. 
Clarke, A.M. and Clarke, A.D.D. 1974. Mental deficiency: The changing outlook (3rd. Ed) London: Methuen.

Crowe, D. 1991. The Roma (Gypsies) in Hungary through the Kadar era. Nationalities Papers. 19 (3), pp. 297-311.

Czeizel, A., Lányi-Engelmayer, A., Klujber, L., Métneki, J. and Tusnády, G. 1980. Etiological study of mental retardation in Budapest, Hungary. American Journal of Mental Deficiency. 85 (2), pp. 120-128.

Eliason, A. 2017. With no deliberate speed: The segregation of Roma children in Europe. Duke Journal of Comparative E International Law. 27, pp. 191-241.

Horváth and Kiss v. Hungary 2013. European Court of Human Rights Application no. 11146/11.

Lanyi-Engelmayer, A., Katona, F. and Czeizel, A. 1983. Current issues in mental retardation in Hungary. Applied Research in Mental Retardation. 4 (2), pp. 123-138.

Majtényi, B. and Majtényi, G. 2016. A Contemporary History of Exclusion: The Roma Issue in Hungary from 1945 to 2015. Budapest: Central European University Press.

McCagg, W.O. 1991. Gypsy policy in socialist Hungary and Czechoslovakia, 1945-1989. Nationalities Papers. 19 (3), pp. 313-336.

Pickette, J. 2015. Madness on the margins: Biopolitics and Roma school segregation in the case. Horváth and Kiss v. Hungary. Budapest: CEU.

Sarason, S.B. and Doris, J. 1979. Educational handicap, public policy, and social history: A broadened perspective on mental retardation. New York: Free Press.

Szénássy, E. 2017. Finding space for Romani women within the EU. In: Kováts, E. ed. The Future of the European Union. Feminist perspectives from East-Central Europe. Budapest: Friedrich-Ebert-Stiftung, pp. 37-45. Szondy, M. and Szentágothai, K.R. 1981. Assessment and management of mental retardation in Hungary. Applied Research in Mental Retardation. 2 (2), pp. 139-144.

Van Niekerk, P. A. 1979. The orthopaedagogical within the pedagogical. South African Journal of Pedagogy. 13 (1), pp. 183-191.

Varsa, E. 2017. "The (final) solution of the Gypsy-question:" continuities in discourses about Roma in Hungary, 1940s-1950s. Nationalities Papers. 45 (1), pp. 114-130. 